\title{
First-Principles Calculations on Atomic and Electronic Properties of Ge/4H-SiC Heterojunction
}

\author{
Bei Xu, ${ }^{1}$ Changjun Zhu, ${ }^{1}$ Xiaomin He, ${ }^{2}$ Yuan Zang, ${ }^{2}$ Shenghuang Lin, ${ }^{3}$ \\ Lianbi Li $(1),{ }^{1}$ Song Feng $\left(\mathbb{0},{ }^{1}\right.$ and Qianqian Lei ${ }^{1}$ \\ ${ }^{1}$ School of Science, Xian Polytechnic University, Xian 710048, China \\ ${ }^{2}$ Department of Electronic Engineering, Xian University of Technology, Xian 710048, China \\ ${ }^{3}$ Department of Applied Physics, The Hong Kong Polytechnic University, Hung Hom, Hong Kong \\ Correspondence should be addressed to Lianbi Li; xpu_lilianbi@163.com
}

Received 26 October 2017; Revised 16 January 2018; Accepted 10 February 2018; Published 20 March 2018

Academic Editor: Mohindar S. Seehra

Copyright (C) 2018 Bei Xu et al. This is an open access article distributed under the Creative Commons Attribution License, which permits unrestricted use, distribution, and reproduction in any medium, provided the original work is properly cited.

\begin{abstract}
First-principles calculation is employed to investigate atomic and electronic properties of $\mathrm{Ge} / \mathrm{SiC}$ heterojunction with different Ge orientations. Based on the density functional theory, the work of adhesion, relaxation energy, density of states, and total charge density are calculated. It is shown that $\mathrm{Ge}(110) / 4 \mathrm{H}-\mathrm{SiC}(0001)$ heterointerface possesses higher adhesion energy than that of $\mathrm{Ge}(111) / 4 \mathrm{H}-\mathrm{SiC}(0001)$ interface, and hence $\mathrm{Ge} / 4 \mathrm{H}-\mathrm{SiC}(0001)$ heterojunction with $\mathrm{Ge}[110]$ crystalline orientation exhibits more stable characteristics. The relaxation energy of $\mathrm{Ge}(110) / 4 \mathrm{H}-\mathrm{SiC}(0001)$ heterojunction interface is lower than that of $\mathrm{Ge}(111) / 4 \mathrm{H}$ $\mathrm{SiC}(0001)$ interface, indicating that $\mathrm{Ge}(110) / 4 \mathrm{H}-\mathrm{SiC}(0001)$ interface is easier to form at relative low temperature. The interfacial bonding is analysed using partial density of states and total charge density distribution, and the results show that the bonding is contributed by the Ge-Si bonding.
\end{abstract}

\section{Introduction}

$\mathrm{SiC}$ semiconductor has become one of the most excellent materials for ultraviolet-sensitive devices owing to its wide bandgap $[1,2]$. However, it is not sensitive to the infrared and visible light region. $\mathrm{Ge} / \mathrm{SiC}$ heterojunction was employed to solve the problem, in which the Ge layer of micronanostructure was used as an absorption layer for nearinfrared (NIR) light [3]. By using the $\mathrm{Ge} / \mathrm{SiC}$ heterojunction, SiC-based NIR light-operated device could be realized. The $\mathrm{Ge} / 4 \mathrm{H}-\mathrm{SiC}$ heterostructures are prepared by using low pressure chemical vapor deposition (LPCVD) on $4 \mathrm{H}-\mathrm{SiC}(0001)$ substrates. Details of the growth process could be found in [4-6]. However, the lattice mismatch between Ge(111) primitive cell $\left(a_{\mathrm{Ge}(111)}=4.000 \AA\right)$ and $4 \mathrm{H}-\mathrm{SiC}(0001)$ primitive cell $\left(a_{4 \mathrm{H}-\mathrm{SiC}(0001)}=3.078 \AA\right)$ is as large as $23.0 \%$, which can cause distortion or even dislocation near the interface, leading to a poor crystalline quality of the Ge epilayer. Hence, it is necessary and imperative to investigate the atomic and electronic properties of the $\mathrm{Ge} / \mathrm{SiC}$ heterojunction.
First-principles calculation based on density functional theory (DFT) has been widely used as an important microscopic study method in recent years. The first-principles calculation can be implemented to predict material properties and, consequently, a lot of valuable results have been achieved. Li et al. [7] used the first-principles method to investigate the interface adhesion energy, interface energy, interface fracture toughness, and electronic structure of the $\beta-\operatorname{SiC}(111) / \alpha-\operatorname{Ti}(0001)$ heterojunction. Six kinds of $\mathrm{C}$ terminated $\beta-\mathrm{SiC}(111) / \alpha$-Ti(0001) models were established to study the effect of stack position and inclination angle on interface bonding and fracture toughness. Lin et al. [8] investigated the atomic structures and electronic properties of interfaces between aluminum and four kinds of ceramics with different orientations. They discovered that aluminum metal carbide interface is more stable than aluminum metal nitrides interface and, moreover, the (111) interfaces were found to possess the largest adhesion energy. $\mathrm{He}$ et al. $[9,10]$ studied the $\mathrm{Si}(111) / 6 \mathrm{H}-\mathrm{SiC}(0001)$ heterojunction by using the first-principles. It is found that 


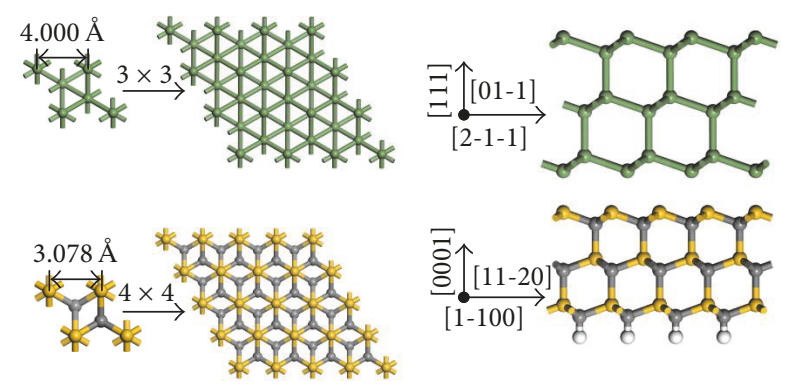

Figure 1: A schematic of Ge(111)/4H-SiC(0001) heterointerface model.

the Si-terminated $\mathrm{Si}(111) / 6 \mathrm{H}-\mathrm{SiC}(0001)$ heterojunction has higher adhesion energy and lower relaxation degree than Cterminated $\mathrm{Si}(111) / 6 \mathrm{H}-\mathrm{SiC}(0001)$ heterojunction. Xu et al. [11] have studied interfacial properties and electronic structure of $\mathrm{Al}(111) / 4 \mathrm{H}-\mathrm{SiC}(0001)$ interface.

In this paper, we present first-principles calculations of adhesion energy, relaxation energy, density of states, and total charge density of $\mathrm{Ge}(111) / 4 \mathrm{H}-\mathrm{SiC}(0001)$ interface and $\mathrm{Ge}(110) / 4 \mathrm{H}-\mathrm{SiC}(0001)$ interface, while analysing the electronic structure, geometry property, and the corresponding physical picture. Furthermore, the first-principles methods are used to investigate the structure of $\mathrm{Ge} / \mathrm{SiC}$ heterointerface, which can provide a theoretical basis for the growth of $\mathrm{Ge} / \mathrm{SiC}$ heterojunctions in experiment.

\section{Methods}

All the calculations in this work were implemented by using the Cambridge Serial Total Energy Package (CASTEP) Code $[12,13]$, which are based on the density functional theory (DFT) [14]. Generalized gradient approximation (GGA) of Perdew-Burke-Ernzerhof (PBE) scheme was employed to describe the exchange-correlation functional [15]. By comparing the lattice constants of GGA(PBE) and local density approximation (LDA) [16] with Caperlay-Alder PerdewZunger (CA-PZ) approximation algorithms, it is shown that the deviation of GGA(PBE) is smaller than that of LDA(CA$\mathrm{PZ})$. Therefore, the GGA-PBE function is implemented in the following $\mathrm{Ge} / 4 \mathrm{H}-\mathrm{SiC}(0001)$ heterojunction calculation. In order to make the system stable and the calculation speed optimal, plane wave cut-off energy was selected as $550 \mathrm{eV}$ for a bulk, a surface, and an interface. The sampling of irreducible edge of Brillouin zone was performed with a regular Monkhorst-Pack grid with $7 \times 7 \times 7 \mathrm{k}$ points for the bulk and $5 \times 5 \times 1 \mathrm{k}$ points for the surface and interface, respectively. The SCF convergence threshold was $2.0 \times 10^{-6} \mathrm{eV} /$ atom, and the convergence tolerance for energy was selected as $2.0 \times$ $10^{-5} \mathrm{eV} /$ atom. The force tolerance, stress, and displacement tolerance were set as $0.05 \mathrm{eV} / \AA, 0.1 \mathrm{GPa}$, and $0.002 \AA$, respectively. To avoid interaction between surface atoms, a vacuum layer of $13 \AA$ was selected for each surface and interface system.

\section{Results and Discussions}

3.1. Ge/4H-SiC Heterojunction Model. Figure 1 displays the interface structure of the $\mathrm{Ge}(111) / 4 \mathrm{H}-\mathrm{SiC}(0001)$ heterojunction based on the TEM characterizations [3]. The primitive cells of $\mathrm{Ge}(111)$ surface and $4 \mathrm{H}-\mathrm{SiC}(0001)$ surface possess lattice constants of $[01-1]_{\mathrm{Ge}}=4.000 \AA,[11-20]_{\mathrm{SiC}}=3.078 \AA$. The lattice matching is $3: 4$ of $\mathrm{Ge}$ to $\mathrm{SiC}$ with a residual mismatch of $2.60 \%$ in the two parallel orientations using the smallest supercell mismatch. In order to saturate suspension bonding, $\mathrm{H}$ atoms are employed to passivate the surface. Figure 2 shows the $\mathrm{Ge}(110) / 4 \mathrm{H}-\mathrm{SiC}(0001)$ heterojunction. The primitive cells of $\mathrm{Ge}(110)$ surface and $4 \mathrm{H}-\mathrm{SiC}(0001)$ surface with constants lattice of $[001]_{\mathrm{Ge}}=5.658 \AA,[1-10]_{\mathrm{Ge}}=$ $4.000 \AA,[10-10]_{\mathrm{SiC}}=5.331 \AA$, and $[-12-10]_{\mathrm{SiC}}=3.078 \AA$ are cleaved due to the $\mathrm{Ge}[110]$ growth orientation on $4 \mathrm{H}$ $\mathrm{SiC}(0001)$. The lattice matching is revealed as $1: 1 \mathrm{Ge}$ to $\mathrm{SiC}$ with a residual mismatch of $-5.78 \%$ and $3: 4 \mathrm{Ge}$ to $\mathrm{SiC}$ with a lattice mismatch of $2.60 \%$ in the two parallel orientations. The interlayer distances of $\mathrm{Ge}(111) / 4 \mathrm{H}-\mathrm{SiC}(0001)$ interface and $\mathrm{Ge}(110) / 4 \mathrm{H}-\mathrm{SiC}(0001)$ interface are optimized by energy calculation before evaluating the interfacial properties of heterostructures. The functional relationship between energy and interlayer spacing is shown in Figure 3. Both of the $\mathrm{Ge}(111) / 4 \mathrm{H}-\mathrm{SiC}(0001)$ and $\mathrm{Ge}(110) / 4 \mathrm{H}-\mathrm{SiC}(0001)$ heterostructures have the same optimized interlayer distances of $2.30 \AA$. Similar conclusions are given in [17].

Because of the large lattice mismatch strain, the lattice mismatch between $4 \mathrm{H}-\mathrm{SiC}$ and $\mathrm{Ge}$ is totally accommodated by misfit dislocations (MD) rather than by uniform elastic strains $[1,2]$. The lattice mismatch of the Ge/4H$\mathrm{SiC}$ interfaces can be calculated, as shown in Table 1 . The $\mathrm{Ge}(111) / 4 \mathrm{H}-\mathrm{SiC}(0001)$ interface has the same 3:4 Ge-to-SiC matching mode with a residual mismatch of $2.60 \%$ along both the $\mathrm{Ge}[01-1]$ and $\mathrm{Ge}[2-1-1]$ orientations. In contrast, the situation of the $\mathrm{Ge}(110) / 4 \mathrm{H}-\mathrm{SiC}(0001)$ interface is different, along $\mathrm{Ge}[1-10]$ orientation, the Ge-to-SiC matching mode is still 3:4; along the vertical orientation of Ge[001], the Geto-SiC mode changes to $1: 1$ and the residual mismatch changes to $-5.78 \%$ correspondingly. The MD densities of the $\mathrm{Ge}(111) / 4 \mathrm{H}-\mathrm{SiC}(0001)$ interface and $\mathrm{Ge}(110) / 4 \mathrm{H}-\mathrm{SiC}(0001)$ interface are as low as $5.334 \times 10^{14} \mathrm{~cm}^{-2}$ and $1.523 \times 10^{14} \mathrm{~cm}^{-2}$, 


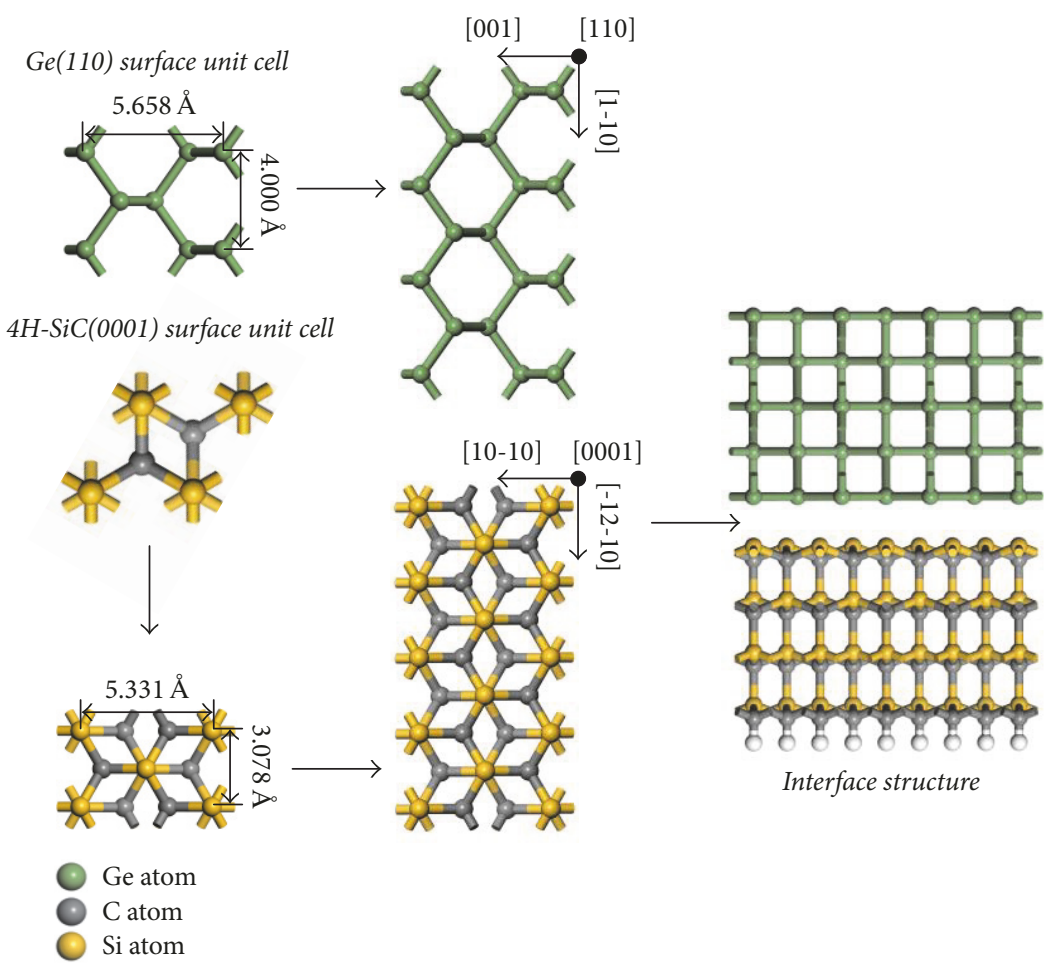

FIgURE 2: A schematic of $\mathrm{Ge}(110) / 4 \mathrm{H}-\mathrm{SiC}(0001)$ heterointerface model.

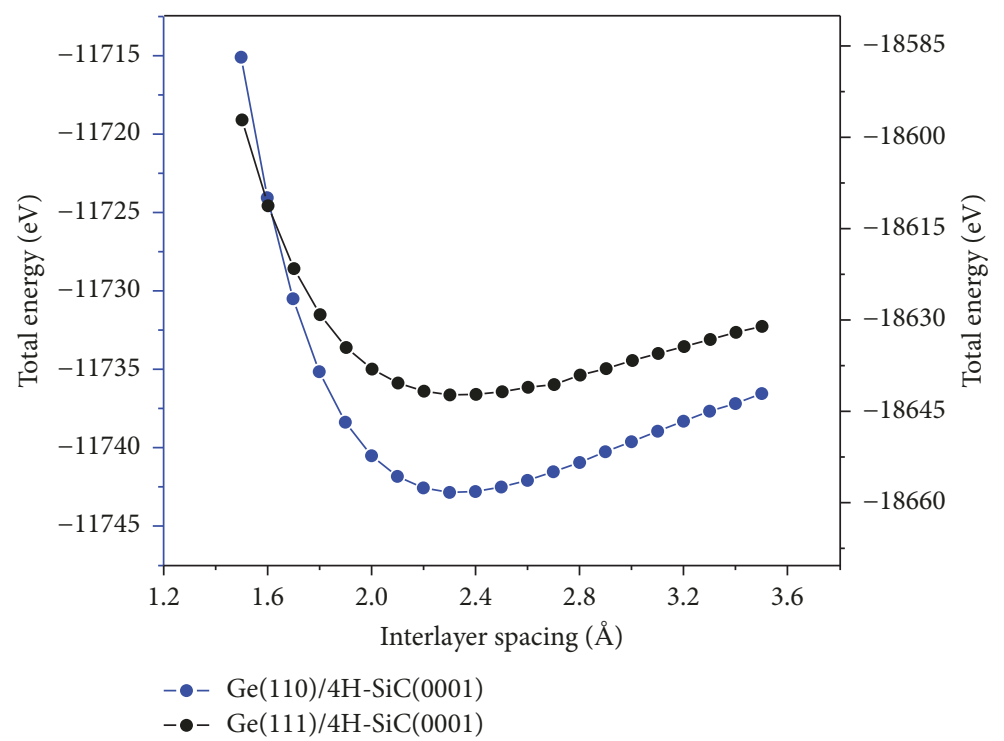

FIGURE 3: The interlayer spacing of $\mathrm{Ge}(110) / 4 \mathrm{H}-\mathrm{SiC}(0001)$ and $\mathrm{Ge}(111) / 4 \mathrm{H}-\mathrm{SiC}(0001)$ heterointerfaces.

respectively, as shown in Table 1 . In addition, the $\mathrm{Ge}(110) / 4 \mathrm{H}-$ $\mathrm{SiC}(0001)$ interface has fewer defects than the $\mathrm{Ge}(111) / 4 \mathrm{H}$ $\mathrm{SiC}(0001)$ interface.

\subsection{Heterointerfaces Properties}

3.2.1. Adhesion Energy and Relaxation Energy. To gain an insight into the binding strength of the interface, we calculated the work of adhesion $\left(W_{\mathrm{ad}}\right)$, which is defined as the reversible work to separate an interface into two free surfaces given by the difference in total energy between the interface and its initial isolated slabs according to the following formula [18-20]:

$$
W_{\mathrm{ad}}=\frac{\left(E_{\mathrm{Ge}}+E_{\mathrm{SiC}}-E_{\mathrm{Ge} / 4 \mathrm{H}-\mathrm{SiC}}\right)}{(N A)},
$$

where $E_{\mathrm{Ge}}$ and $E_{\mathrm{SiC}}$ are the total energy of Ge slab and $\mathrm{SiC}$ slab, where one slab remained and the other is replaced by 
TABLE 1: The lattice mismatch of the Ge/4H-SiC heterostructures calculated with the domain matching model.

\begin{tabular}{|c|c|c|c|c|c|}
\hline \multirow{3}{*}{$\begin{array}{l}\text { Growth orientation } \\
\mathrm{Ge}(111) / 4 \mathrm{H}-\mathrm{SiC}(0001)\end{array}$} & \multicolumn{2}{|c|}{$\begin{array}{c}\text { Ge-to-SiC } \\
\text { matching mode }\end{array}$} & \multicolumn{2}{|c|}{ Residual mismatch } & \multirow[t]{2}{*}{ MD density } \\
\hline & $\mathrm{Ge}[01-1]$ & $\mathrm{Ge}[2-1-1]$ & $\mathrm{Ge}[01-1]$ & $\mathrm{Ge}[2-1-1]$ & \\
\hline & $\mathrm{SiC}[11-20]$ & $\mathrm{SiC}[1-100]$ & $\mathrm{SiC}[11-20]$ & $\mathrm{SiC}[1-100]$ & $5.334 \times 10^{14} \mathrm{~cm}^{-2}$ \\
\hline & $3: 4$ & $3: 4$ & $2.60 \%$ & $2.60 \%$ & \\
\hline \multirow{2}{*}{$\mathrm{Ge}(110) / 4 \mathrm{H}-\mathrm{SiC}(0001)$} & $\begin{array}{c}\mathrm{Ge}[001] \\
\mathrm{SiC}[10-10]\end{array}$ & $\begin{array}{c}\mathrm{Ge}[1-10] \\
\mathrm{SiC}[-12-10]\end{array}$ & $\begin{array}{c}\mathrm{Ge}[001] \\
\mathrm{SiC}[10-10]\end{array}$ & $\begin{array}{c}\mathrm{Ge}[1-10] \\
\mathrm{SiC}[-12-10]\end{array}$ & $1.523 \times 10^{14} \mathrm{~cm}^{-2}$ \\
\hline & $1: 1$ & $3: 4$ & $-5.78 \%$ & $2.60 \%$ & \\
\hline
\end{tabular}

TABLE 2: Unrelaxed and relaxed $E_{\mathrm{Ge}}, E_{4 \mathrm{H}-\mathrm{SiC}(0001)}, E_{\mathrm{Ge} / 4 \mathrm{H}-\mathrm{SiC}}$, and $W_{\mathrm{ad}}$.

\begin{tabular}{lcccc}
\hline & $E_{\mathrm{Ge}(111)}(\mathrm{eV})$ & $E_{4 \mathrm{H}-\mathrm{SiC}(0001)}(\mathrm{eV})$ & $E_{\mathrm{Ge}(111) / 4 \mathrm{H}-\mathrm{SiC}(0001)}(\mathrm{eV})$ & $W_{\mathrm{ad}}\left(\mathrm{J} / \mathrm{m}^{2}\right)$ \\
\hline Unrelaxed & -5777.006 & -12844.091 & -18642.163 & 0.104 \\
Relaxed & -5777.551 & -12845.745 & -18644.926 & 0.106 \\
\hline & $E_{\mathrm{Ge}(110)}(\mathrm{eV})$ & $E_{4 \mathrm{H}-\mathrm{SiC}(0001)}(\mathrm{eV})$ & $E_{\mathrm{Ge}(110) / 4 \mathrm{H}-\mathrm{SiC}(0001)}(\mathrm{eV})$ & $W_{\mathrm{ad}}\left(\mathrm{J} / \mathrm{m}^{2}\right)$ \\
\hline Unrelaxed & -3207.981 & -8523.457 & -11742.871 & 0.193 \\
Relaxed & -3208.026 & -8524.842 & -11746.039 & 0.222 \\
\hline
\end{tabular}

TABLE 3: Relaxation energies of $\mathrm{Ge}(111) / 4 \mathrm{H}-\mathrm{SiC}(0001)$ and $\mathrm{Ge}(110) / 4 \mathrm{H}-\mathrm{SiC}(0001)$ interfaces.

\begin{tabular}{lccc}
\hline Heterojunction & $E_{\text {total }}^{\prime}(\mathrm{eV})$ & $E_{\text {total }}(\mathrm{eV})$ & $E_{\text {relaxion }}(\mathrm{eV} /$ atom $)$ \\
\hline $\mathrm{Ge}(111) / 4 \mathrm{H}-\mathrm{SiC}(0001)$ & -18642.163 & -18644.926 & -0.017 \\
$\mathrm{Ge}(110) / 4 \mathrm{H}-\mathrm{SiC}(0001)$ & -11742.871 & -11746.039 & -0.030 \\
\hline
\end{tabular}

vacuum in the same supercell, respectively. $E_{\mathrm{Ge} / 4 \mathrm{H}-\mathrm{SiC}}$ denotes the total energy of the interface system, $N$ is the number of atoms at the interface in the model, and $A$ is the interfacial area. Based on (1), the variable values are obtained and listed in Table 2.

In addition, the relaxation energy $E_{\text {relaxion }}$ can be determined by an expression as follows:

$$
E_{\text {relaxion }}=\frac{\left(E_{\text {total }}-E_{\text {total }}^{\prime}\right)}{N}
$$

where $E_{\text {total }}^{\prime}$ and $E_{\text {total }}$ are the total energies of the unrelaxed and relaxed interface systems, respectively, and $N$ is the number of atoms in the system. Based on (2), the variable values are obtained and listed in Table 3 .

Table 2 shows that the bonding energy of the unrelaxed interface is smaller than that of the relaxed one, indicating that the relaxed interface is more stable. It is also shown that the adhesion energy of $\mathrm{Ge}(110) / 4 \mathrm{H}-\mathrm{SiC}(0001)$ interface is higher than that of the $\mathrm{Ge}(111) / 4 \mathrm{H}-\mathrm{SiC}(0001)$ interface, indicating that $\mathrm{Ge}(110) / 4 \mathrm{H}-\mathrm{SiC}(0001)$ heterointerface is more energetically stable than $\mathrm{Ge}(111) / 4 \mathrm{H}-\mathrm{SiC}(0001)$ heterointerface. As shown in Table 3, the relaxation energy of $\mathrm{Ge}(110) / 4 \mathrm{H}-\mathrm{SiC}(0001)$ interface is lower than that of $\mathrm{Ge}(111) / 4 \mathrm{H}-\mathrm{SiC}(0001)$ interface, suggesting that $\mathrm{Ge}(110)$ films are easier to deposit on $4 \mathrm{H}-\mathrm{SiC}(0001)$ substrates at relative low temperatures, which is consistent with the conclusions in [6].

The influence of relaxation on the atom positions at the $\mathrm{Ge} / 4 \mathrm{H}-\mathrm{SiC}$ interfaces is investigated. Figures $4(\mathrm{a})$ and $4(\mathrm{~b})$ represent the atom-stacking structures of the post-optimized
$\mathrm{Ge}(110) / 4 \mathrm{H}-\mathrm{SiC}(0001)$ interface and $\mathrm{Ge}(111) / 4 \mathrm{H}-\mathrm{SiC}(0001)$ interface, respectively. It is shown that the position of atoms near the interface deviates from the original position to some extent, displaying certain displaces. To quantitatively compare the extent of relaxation between $\mathrm{Ge}(110) / 4 \mathrm{H}-\mathrm{SiC}(0001)$ and $\mathrm{Ge}(111) / 4 \mathrm{H}-\mathrm{SiC}(0001)$ interface, corresponding variations of $X Y Z$ coordinates and variations of distance were calculated, as shown in Figures 4(c)-4(j). The first and second layers of atoms at the interface severely deviate from the equilibrium position. Approaching to the bulk materials, the deviations decrease drastically, suggesting that, as the interface formed, merely one or two layers of atoms at the interface were significantly influenced. In the meantime, one can also observe that at the interface the variation of $\mathrm{Ge}$ atoms is larger than that of $\mathrm{SiC}$ atoms, indicating that the relaxation occurs mainly on the Ge side. It is shown that the variation of atoms in Figure 4(d) is larger than that in Figure 4(c), which is attributed to the fact that the lattice mismatch in the $Y$ direction is greater than that in the $X$ direction at the $\mathrm{Ge}(110) / 4 \mathrm{H}-\mathrm{SiC}(0001)$ interface. However, the variation of the atoms in Figure $4(\mathrm{~g})$ is almost the same as that in Figure 4(h), since the lattice mismatch in the $Y$ direction is commensurate to that in the $X$ direction at the $\mathrm{Ge}(111) / 4 \mathrm{H}$ $\mathrm{SiC}(0001)$ interface.

3.2.2. Electronic Structure and Bonding. In order to understand the essence of bonds of $\mathrm{Ge}(111) / 4 \mathrm{H}-\mathrm{SiC}(0001)$ and $\mathrm{Ge}(110) / 4 \mathrm{H}-\mathrm{SiC}(0001)$ interfaces, the total charge density and charge density difference of $\mathrm{Ge}(111) / 4 \mathrm{H}-\mathrm{SiC}(0001)$ and $\mathrm{Ge}(110) / 4 \mathrm{H}-\mathrm{SiC}(0001)$ interfaces are calculated, as shown in Figures 5(a)-5(d), respectively. High charge accumulation 


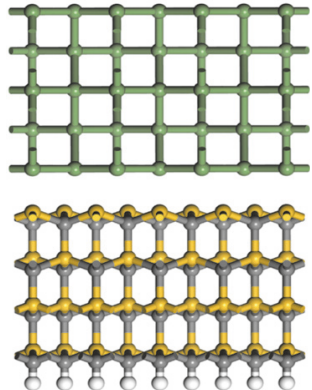

(a)

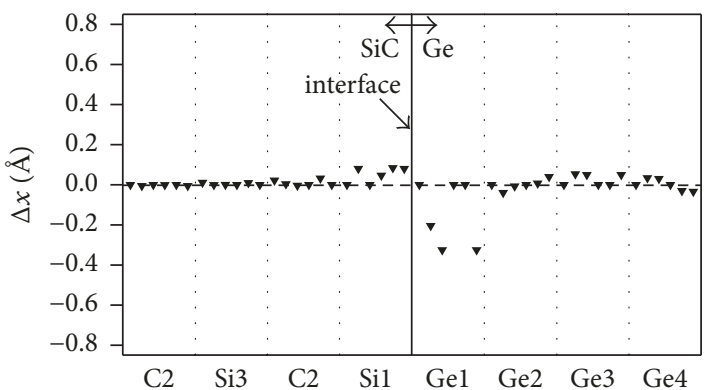

(c)

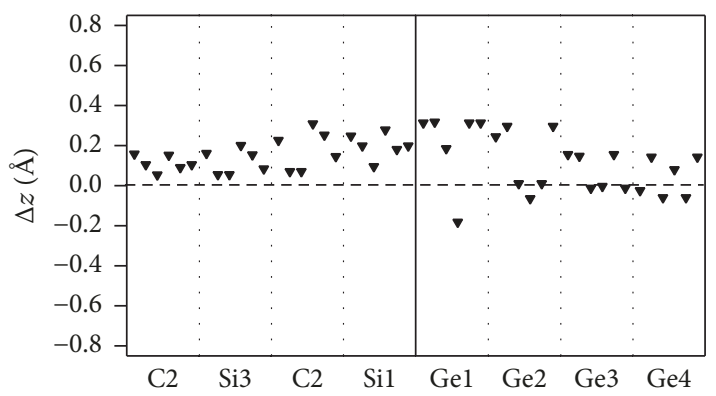

(e)

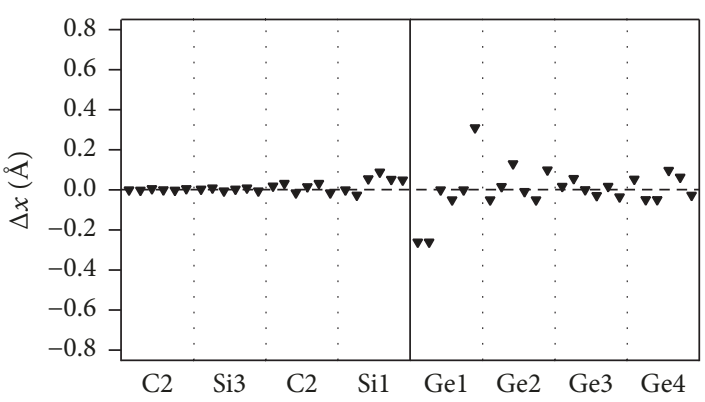

(g)

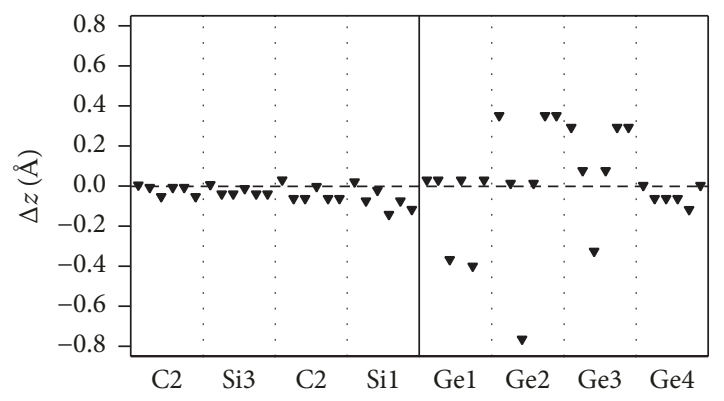

(i)

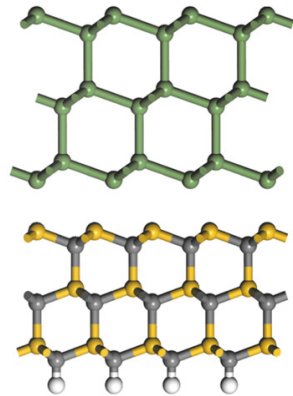

(b)

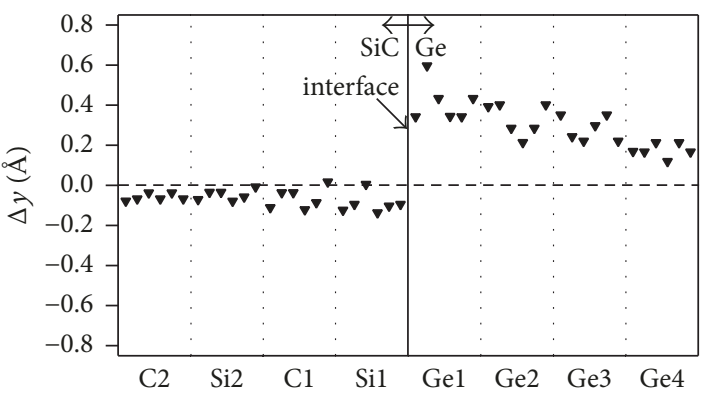

(d)

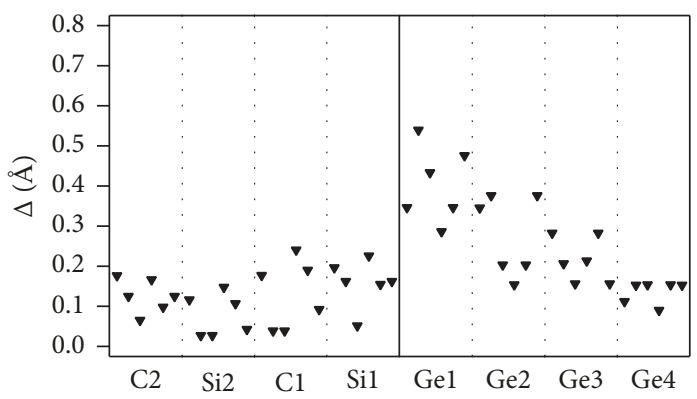

(f)

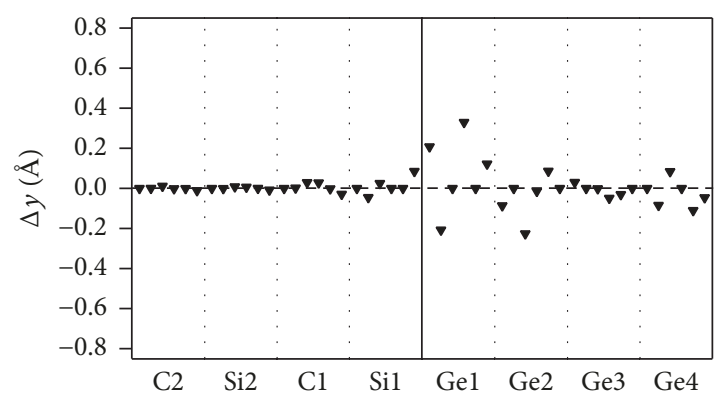

(h)

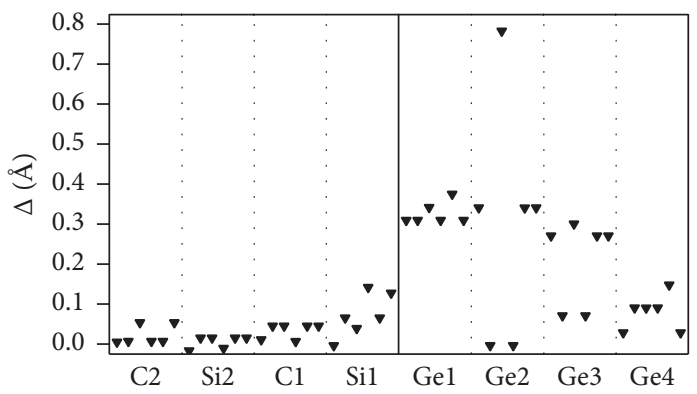

(j)

FIGURE 4: $\mathrm{Ge}(110) / 4 \mathrm{H}-\mathrm{SiC}(0001)$ heterointerface and variations of $X Y Z$ coordinates and variation of distance are shown in (a) and (c-f), respectively. $\mathrm{Ge}(111) / 4 \mathrm{H}-\mathrm{SiC}(0001)$ heterointerface and variations of $X Y Z$ coordinates and variation of distance are shown in (b) and (g-j), respectively. 


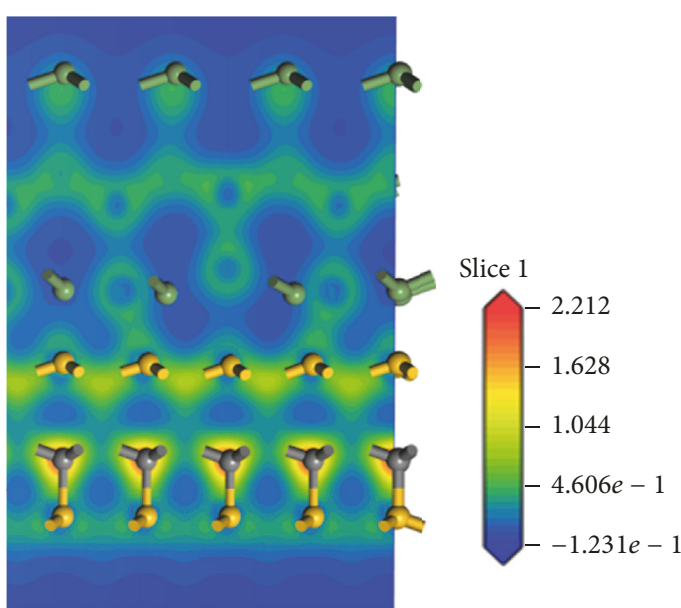

(a)

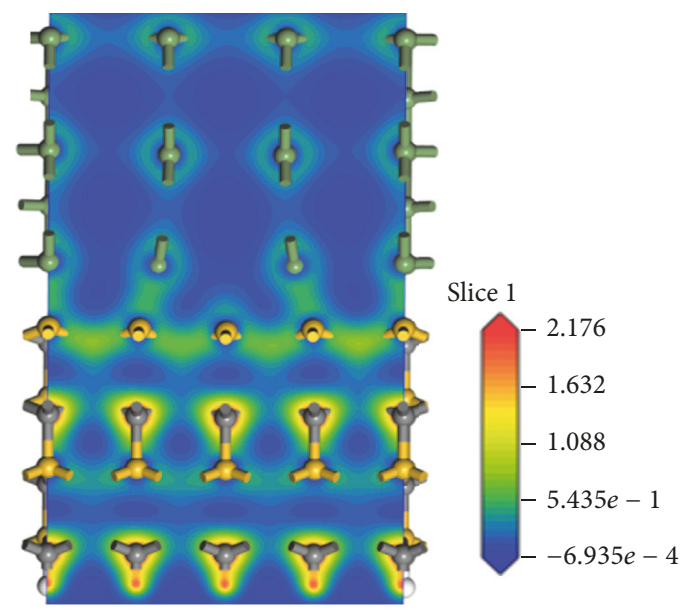

(c)

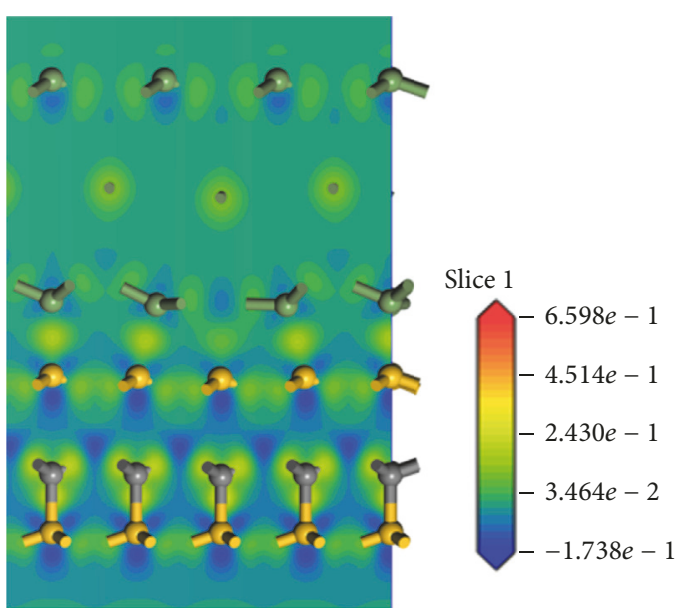

(b)

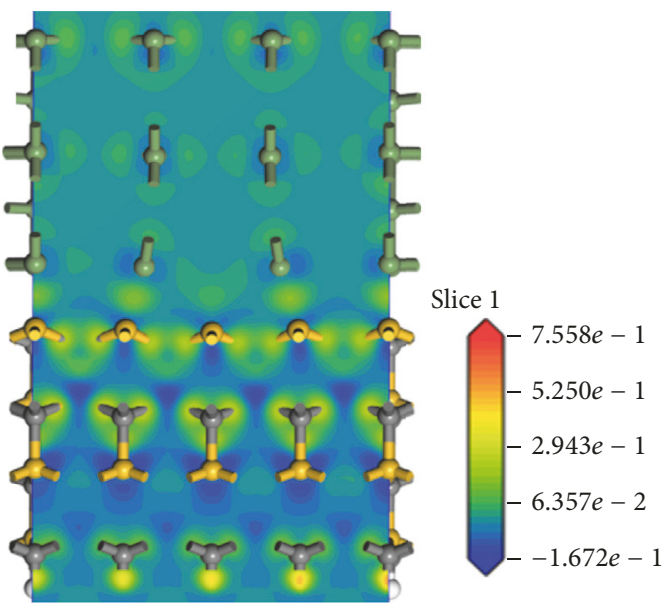

(d)

Figure 5: Total charge density for $\mathrm{Ge}(111) / 4 \mathrm{H}-\mathrm{SiC}(0001)$ (a) and $\mathrm{Ge}(110) / 4 \mathrm{H}-\mathrm{SiC}(0001)$ heterojunction (c). The charge density difference for $\mathrm{Ge}(111) / 4 \mathrm{H}-\mathrm{SiC}(0001)(\mathrm{b})$ and $\mathrm{Ge}(110) / 4 \mathrm{H}-\mathrm{SiC}(0001)$ heterojunction (d).

appears between interfacial $\mathrm{Ge}$ and $\mathrm{Si}$ atom at the $\mathrm{Ge}(111) / 4 \mathrm{H}-$ $\mathrm{SiC}(0001)$ interface, indicating that $\mathrm{Ge}-\mathrm{Si}$ bonding is formed at the interface. The charge density difference of $\mathrm{Ge}(111) / 4 \mathrm{H}-$ $\mathrm{SiC}(0001)$ interface is displayed in Figure 5(b). The blue areas represent the depletion region of the charges, and the yellow areas show the accumulation region of the charge. It is shown that an extremely large amount of charges, which mainly come from the bulk materials near the interface, accumulated at the $\mathrm{Ge}(111) / 4 \mathrm{H}-\mathrm{SiC}(0001)$ interface, suggesting the formation of Ge-Si bonding at interface due to the transfer of bulk materials. For $\mathrm{Ge}(110) / 4 \mathrm{H}-\mathrm{SiC}(0001)$ interfaces, there are lots of charge accumulation between $\mathrm{Ge}$ atom of Ge crystal and $\mathrm{Si}$ atom of SiC crystal in interface, as shown in Figures 5(c) and 5(d). Therefore, the existence of Ge-Si bonding is proved.

An insight into the bonding properties of $\mathrm{Ge}(110) / 4 \mathrm{H}$ $\mathrm{SiC}(0001)$ interface and $\mathrm{Ge}(111) / 4 \mathrm{H}-\mathrm{SiC}(0001)$ interface are provided by calculating the partial density of states (PDOS) of the interface. The partial density of states (PDOS) of $\mathrm{Ge}(110) / 4 \mathrm{H}-\mathrm{SiC}(0001)$ interface and $\mathrm{Ge}(111) / 4 \mathrm{H}-\mathrm{SiC}(0001)$ interface are shown in Figures 6(a) and 6(b), respectively.
It reveals that relaxation merely occurs in one or two layers of atoms near the interface by analysing atoms position at the interface. For comparison, hereby, the partial density of states (PDOS) of Ge bulk and $4 \mathrm{H}-\mathrm{SiC}$ bulk are displayed in Figures 6(a) and 6(b) as well for comparison, and, as a result, several distinct features can be observed. Firstly, compared to the case of bulk materials, the first and second layers exhibit delocalization and lower density, suggesting that electrons in the first and second layers are transferred into the interface and involved in the formation of bonding. Secondly, the distribution of density of states of the first and second layers shifts from the low energy region to the high energy region as compared to the case of bulk materials, which is largely caused by the rearrangement of the atoms and the formation of the interface. Finally, the distribution of density of states of the first and second layers on the Ge side severely deviates from that of the bulk, showing similarity to the distribution of density of states on the $\mathrm{SiC}$ side. Similar situation occurs on the distribution of density of states of the first and second layers on the $\mathrm{SiC}$ side, indicating that the distribution of 

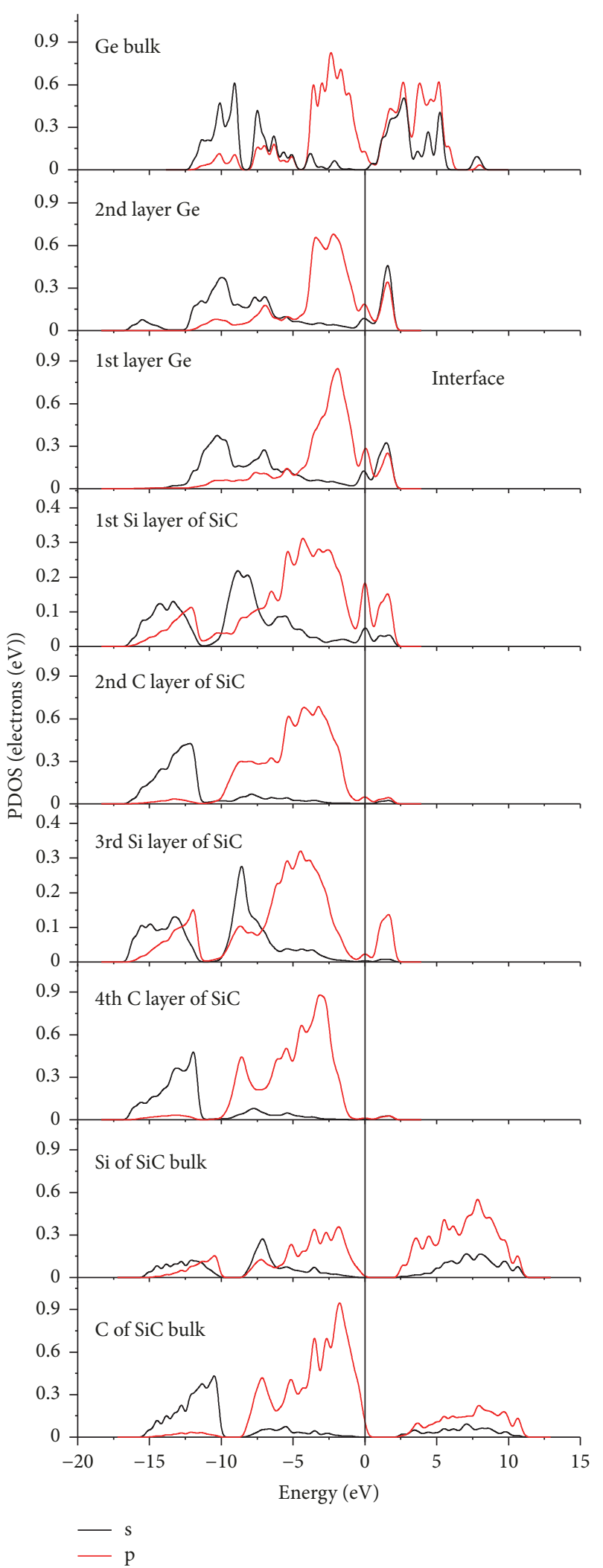

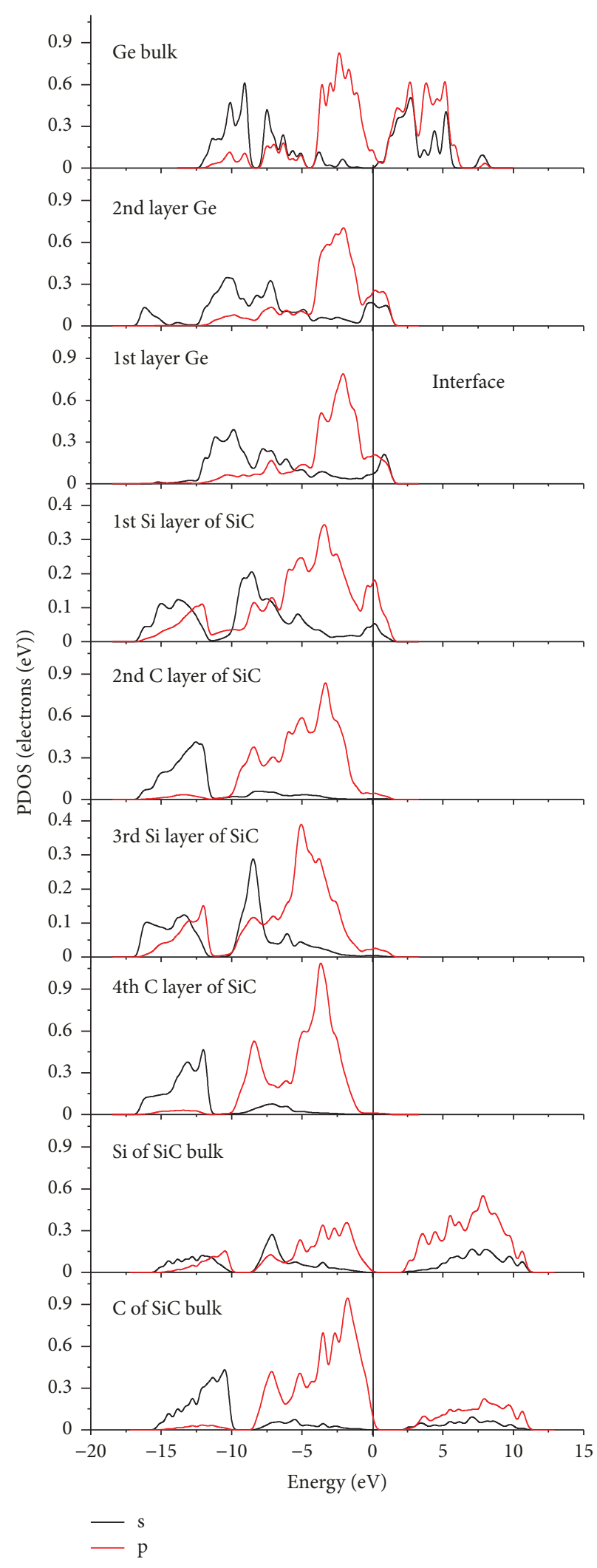

(b)

Figure 6: Partial density of state (PDOS) of Ge(110)/4H-SiC(0001) (a) and Ge(111)/4H-SiC(0001) heterojunctions (b). 
density of states at the interface is influenced by the bulk materials on both sides. As shown in Figure 6(a), on the Ge side, the significant peaks appear in the ranges from $-12.5 \mathrm{eV}$ to $-6 \mathrm{eV},-6 \mathrm{eV}$ to $-5 \mathrm{eV},-5 \mathrm{eV}$ to $1 \mathrm{eV}$, and $1 \mathrm{eV}$ to $2.5 \mathrm{eV}$. The densities of states from $-12.5 \mathrm{eV}$ to $-6 \mathrm{eV}$ and $1 \mathrm{eV}$ to $2.5 \mathrm{eV}$ originate mainly from the Ge- $4 \mathrm{~s},-5 \mathrm{eV}$ to $1 \mathrm{eV}$ is mainly from the Ge-4p, and the Ge-4s and Ge-4p are mixed to the density of states from $-6 \mathrm{eV}$ to $-5 \mathrm{eV}$, indicating the presence of Ge-Ge bonds. The density of states from $-16 \mathrm{eV}$ to $-13 \mathrm{eV}$ is mainly originated from the $\mathrm{C}-2 \mathrm{~s}$ and $\mathrm{Si}-3 \mathrm{~s},-13 \mathrm{eV}$ to $-10 \mathrm{eV}$ is mainly associated with the $\mathrm{C}-2 \mathrm{~s}$ and $\mathrm{Si}-3 \mathrm{p},-10 \mathrm{eV}$ to $-7.5 \mathrm{eV}$ is mostly related to the C-2p and Si- $3 \mathrm{~s}$, and $-7.5 \mathrm{eV}$ to $0 \mathrm{eV}$ is largely originated from the $\mathrm{C}-2 \mathrm{p}$ and $\mathrm{Si}-3 \mathrm{p}$. By comparing with the bulk material, the distribution of density of states at the heterointerface shifts toward low energy slightly. Furthermore, by comparing the $\mathrm{Ge}(110) / 4 \mathrm{H}-\mathrm{SiC}(0001)$ and $\mathrm{Ge}(111) / 4 \mathrm{H}-\mathrm{SiC}(0001)$ heterointerfaces, for the first Ge layer of Ge slab and the first Si layer of $4 \mathrm{H}-\mathrm{SiC}$ slab, several distinct resonance peaks appear in the range of $-4 \mathrm{eV}$ to $0 \mathrm{eV}$ as well. As shown in Figure 6(b), Ge(111)/4H-SiC(0001) heterointerface significant resonance peaks appear as well. The peaks mainly originate from the orbital hybridization of $\mathrm{Si}-3 \mathrm{p}$ and Ge-4P, indicating the formation of Ge-Si bond at the interface.

\section{Conclusions}

First-principles calculations are utilized to gain an insight into the interfacial properties of $\mathrm{Ge} / 4 \mathrm{H}-\mathrm{SiC}$. The stability, electronic structure, and bonding properties of $\mathrm{Ge}(111) / 4 \mathrm{H}-$ $\mathrm{SiC}(0001)$ and $\mathrm{Ge}(110) / 4 \mathrm{H}-\mathrm{SiC}(0001)$ are mainly studied. The works of adhesion of $\mathrm{Ge}(110) / 4 \mathrm{H}-\mathrm{SiC}(0001)$ and $\mathrm{Ge}(111) / 4 \mathrm{H}$ $\mathrm{SiC}(0001)$ interfaces are $0.222 \mathrm{~J} / \mathrm{m}^{2}$ and $0.106 \mathrm{~J} / \mathrm{m}^{2}$, respectively. The work of adhesion of $\mathrm{Ge}(110) / 4 \mathrm{H}-\mathrm{SiC}(0001)$ interface is higher than that of the $\mathrm{Ge}(111) / 4 \mathrm{H}-\mathrm{SiC}(0001)$ interface, leading to that $\mathrm{Ge}(110) / 4 \mathrm{H}-\mathrm{SiC}(0001)$ interface is more stable than $\mathrm{Ge}(111) / 4 \mathrm{H}-\mathrm{SiC}(0001)$ interface. $\mathrm{Ge}(110) / 4 \mathrm{H}-\mathrm{SiC}(0001)$ interface is easier to form at low temperatures due to its lower relaxation energy as compared with $\mathrm{Ge}(111) / 4 \mathrm{H}-\mathrm{SiC}(0001)$ interface. Calculations on the electronic structure and PDOS indicate that the Ge-Si bonds have been formed at the interface, which are mainly due to the orbital hybridization of Si-3p and Ge-4P.

\section{Conflicts of Interest}

The authors declare that they have no conflicts of interest.

\section{Acknowledgments}

This work was supported financially by the National Natural Science Foundation of China (Grants nos. 51402230 and 21503153), the Project Supported by Natural Science Basic Research Plan in Shaanxi Province of China (Grants nos. 2015JM6282 and 2017JM6075), Scientific Research Program Funded by Shaanxi Provincial Education Department (Grants nos. 14JK1302 and 17JK0335), and Doctoral Scientific Research Foundation of Xian University of Technology (Grant no. Y201605).

\section{References}

[1] L. B. Li, Z. M. Chen, Y. Zang, L. X. Song, Y. L. Han, and Q. $\mathrm{Chu}$, "Epitaxial growth of $\mathrm{Si} / \mathrm{SiC}$ heterostructures with different preferred orientations on $6 \mathrm{H}-\mathrm{SiC}(0001)$ by LPCVD," CrystEngComm, vol. 18, no. 30, pp. 5681-5685, 2016.

[2] L. B. Li, Z. M. Chen, Y. Zang, and S. Feng, "Atomic-scale characterization of $\mathrm{Si}(110) / 6 \mathrm{H}-\mathrm{SiC}(0001)$ heterostructure by HRTEM," Materials Letters, vol. 163, pp. 47-50, 2016.

[3] Q. Chu, L. Li, C. Zhu, Y.Zang, S. Lin, and Y. Han, "Preparation of $\mathrm{SiC} / \mathrm{Ge} /$ graphene heterostructure on $4 \mathrm{H}-\mathrm{SiC}(0001)$, , Materials Letters, vol. 211, pp. 133-137, 2018.

[4] Y. L. Han, H. B. Pu, Y. Zang, and L. B. Li, "Epitaxial growth of Ge film on $6 \mathrm{H}-\mathrm{SiC}(0001)$ by LPCVD," Optoelectronics and Advanced Materials - Rapid Communications , vol. 10, no. 9-10, pp. 737-739, 2016.

[5] K. Alassaad, V. Soulière, F. Cauwet et al., "Ge incorporation inside $4 \mathrm{H}$-SiC during homoepitaxial growth by chemical vapor deposition," Acta Materialia, vol. 75, pp. 219-226, 2014.

[6] P. M. Gammon, A. Pérez-Tomás, M. R. Jennings et al., "Interface characteristics of $\mathrm{n}-\mathrm{n}$ and $\mathrm{p}-\mathrm{n} \mathrm{Ge} / \mathrm{SiC}$ heterojunction diodes formed by molecular beam epitaxy deposition," Journal of Applied Physics, vol. 107, no. 12, p. 124512, 2010.

[7] J. Li, Y. Q. Yang, L. L. Li et al., "Interfacial properties and electronic structure of $\beta$-SiC(111)/ $\alpha-\operatorname{Ti}(0001)$ : A first principle study," Journal of Applied Physics, vol. 113, Article ID 023516, 2013.

[8] Z. Lin, X. Peng, T. Fu et al., "Atomic structures and electronic properties of interfaces between aluminum and carbides/ nitrides: A first-principles study," Physica E: Low-dimensional Systems and Nanostructures, vol. 89, pp. 15-20, 2017.

[9] X. M. He, Z. M. Chen, H. B. Pu et al., "First-principles calculations on $\mathrm{Si}(220)$ located $6 \mathrm{H}-\mathrm{SiC}(10 \overline{1} 0)$ surface with different stacking sites," Chinese Physics B, vol. 23, no. 10, Article ID 106802, 2014.

[10] X.-M. He, Z.-M. Chen, L. Huang, and L.-B. Li, "First-principles calculations on atomic and electronic properties of $\mathrm{Si}(111) / 6 \mathrm{H}$ $\mathrm{SiC}(0001)$ heterojunction," Modern Physics Letters B, vol. 29, no. 29, Article ID 1550182, 2015.

[11] X. Xu, H. Wang, M. Zha, C. Wang, Z. Yang, and Q. Jiang, "Effects of $\mathrm{Ti}, \mathrm{Si}, \mathrm{Mg}$ and $\mathrm{Cu}$ additions on interfacial properties and electronic structure of $\mathrm{Al}(111) / 4 \mathrm{H}-\mathrm{SiC}(0001)$ interface: A firstprinciples study," Applied Surface Science, vol. 437, pp. 103-109, 2018.

[12] H. Xiong, Z. Liu, H. Zhang, Z. Du, and C. Chen, "First principles calculation of interfacial stability, energy and electronic properties of SiC/ZrB2 interface," Journal of Physics and Chemistry of Solids, vol. 107, pp. 162-169, 2017.

[13] J. Yang, J. Huang, D. Fan, and S. Chen, "First-principles investigation on the electronic property and bonding configuration of $\mathrm{NbC}(111) / \mathrm{NbN}$ (111) interface," Journal of Alloys and Compounds, vol. 689, pp. 874-884, 2016.

[14] J. Martinez, S. B. Sinnott, and S. R. Phillpot, "Adhesion and diffusion at TiN/TiO2 interfaces: A first principles study," Computational Materials Science, vol. 130, pp. 249-256, 2017.

[15] W. H. Lee and X. H. Yao, "First principle investigation of phase transition and thermodynamic properties of SiC," Computational Materials Science, vol. 106, pp. 76-82, 2015.

[16] M. Piasecki, M. G. Brik, and I. V. Kityk, "Tl4CdI6 - Wide band gap semiconductor: First principles modelling of the structural, electronic, optical and elastic properties," Materials Chemistry and Physics, vol. 163, pp. 562-568, 2015. 
[17] N. Chandran, M. Sall, J. Arvanitidis et al., "On the Formation of Graphene by Ge Intercalation of a $4 \mathrm{H}-\mathrm{SiC}$ Surface," Materials Science Forum, vol. 821-823, pp. 961-964, 2015.

[18] J. Li, Y. Yang, G. Feng, X. Luo, Q. Sun, and N. Jin, "First-principles study of stability and properties on $\beta$-SiC/TiC(111) interface," Journal of Applied Physics, vol. 114, no. 16, Article ID 163522, 2013.

[19] D. Yin, X. Peng, Y. Qin, and Z. Wang, "Electronic property and bonding configuration at the TiN(111)/VN(111) interface," Journal of Applied Physics, vol. 108, no. 3, Article ID 033714, 2010.

[20] D. Y. Dang, L. Y. Shi, J. L. Fan, and H. R. Gong, "First-principles study of W-TiC interface cohesion," Surface and Coatings Technology, vol. 276, pp. 602-605, 2015. 

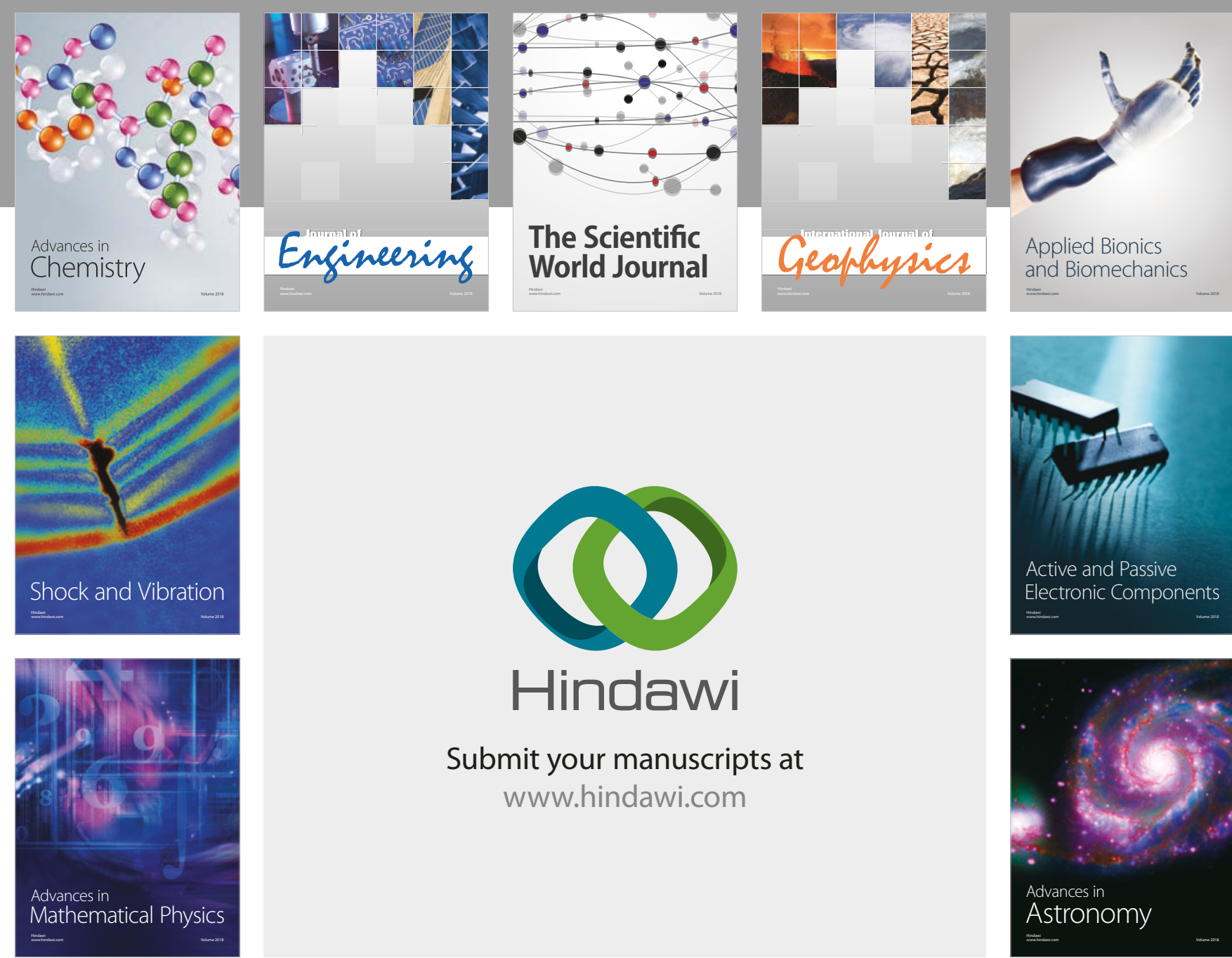

Submit your manuscripts at

www.hindawi.com

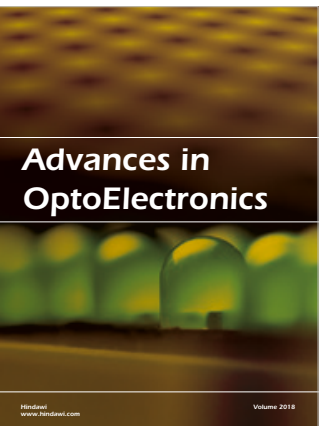

\section{Rotcting Machinery}
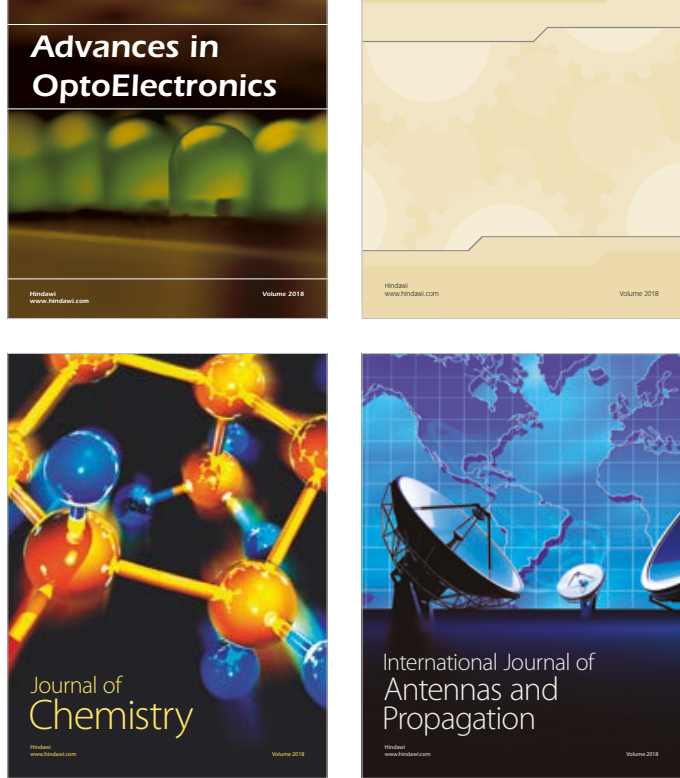

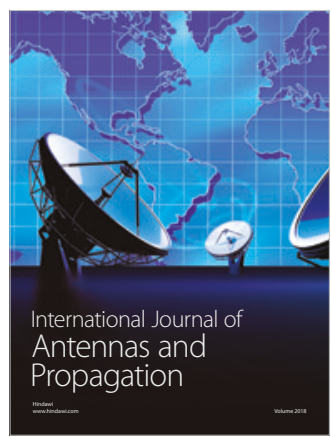

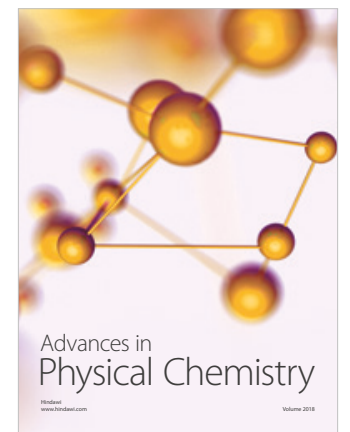

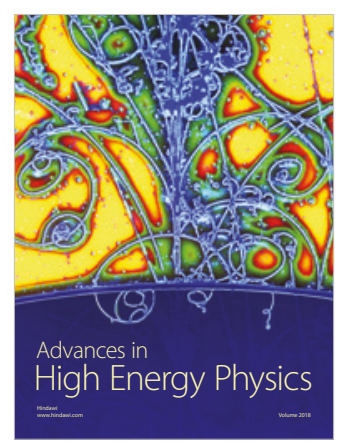

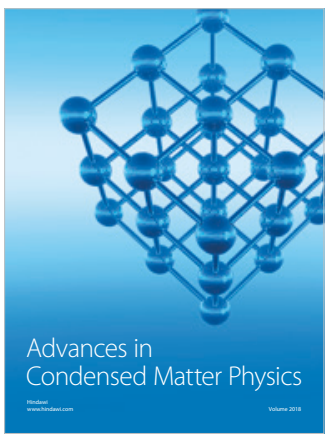

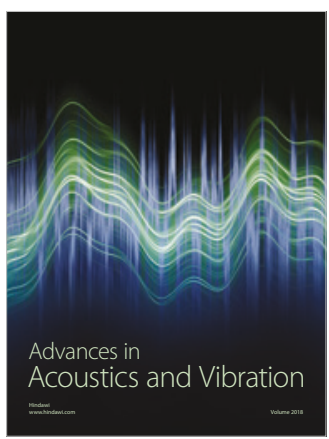

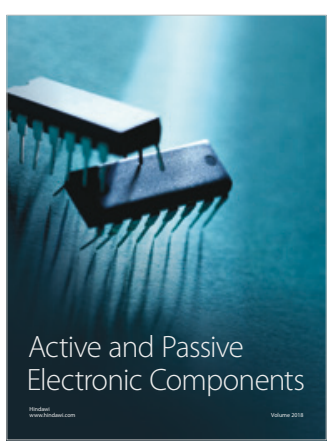
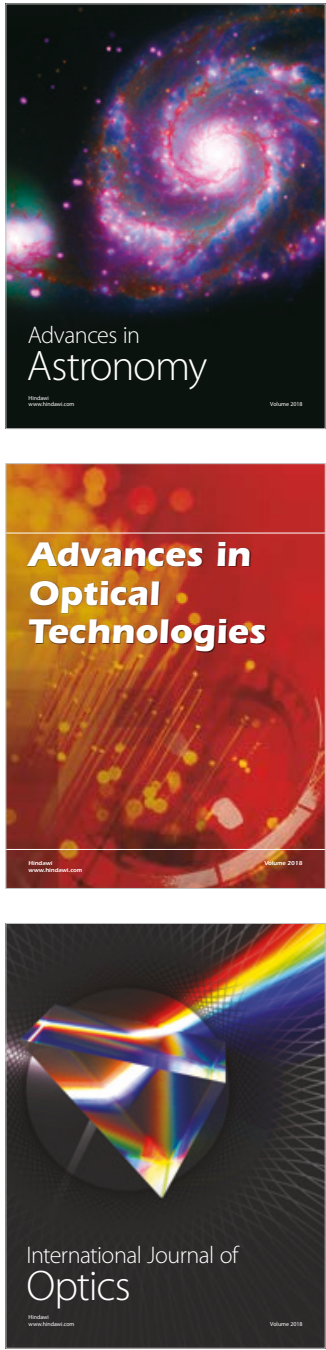